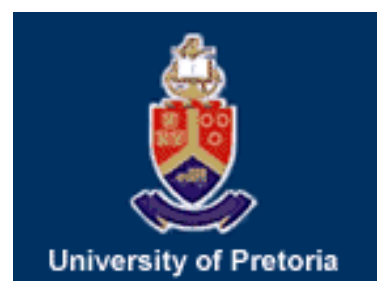

University of Pretoria

Department of Economics Working Paper Series

On the Welfare Equivalence of Asset Markets and Banking in Diamond Dybvig Economies

Alexander Zimper

University of Pretoria

Working Paper: 2013-56

September 2013

Department of Economics

University of Pretoria

0002, Pretoria

South Africa

Tel: +27 124202413 


\title{
On the welfare equivalence of asset markets and banking in Diamond Dybvig economies*
}

\author{
Alexander Zimper ${ }^{\dagger}$
}

September 13, 2013

\begin{abstract}
Why do people choose bank deposit contracts over a direct participation in asset markets? In their seminal paper, Diamond and Dybvig's (1983) answer this question by claiming that bank deposit contracts can implement allocations that are welfare superior to asset markets equilibria. The present paper demonstrates that this claim is false whenever the asset market participants are highly rational.
\end{abstract}

Keywords: Demand deposit contract; Asset market; Asymmetric information JEL Classification Numbers: G14, G21. 


\section{Introduction}

Diamond and Dybvig (1983) (=DD) claim that "bank deposit contracts can provide allocations superior to those of exchange markets" (p. 401). As the reason for this welfare superiority of financial intermediation over asset markets, DD identify asymmetric information about the agents' liquidity preferences:

"Because only the agent ever observes the private information state, it is impossible to write insurance contracts in which the payoff depends directly on private information, without an explicit mechanism for information flow. Therefore, simple competitive markets cannot provide this liquidity insurance. [...] Banks are able to transform illiquid assets by offering liabilities with a different, smoother pattern of returns over time than the illiquid assets offer." (p.403)

This claim of welfare superiority of financial intermediation has been widely accepted within the literature. For example, in their leading textbook Freixas and Rochet (2008) write:

"[...] the market economy does not provide perfect insurance against liquidity shocks and therefore does not lead to an efficient allocation of resources. This is because individual liquidity shocks are not publicly observable, and securities contingent on these shocks cannot be traded [...]. The following discussion shows how a financial intermediary can solve this problem." (p. 23)

The above argumentation refers to the well known fact that any asset market equilibrium is Pareto optimal if this market is complete in the sense that arbitrary trading strategies for state contingent Arrow-Debreu securities are feasible. Consequently, as a necessary condition any welfare superiority of financial intermediation over asset markets could only be possible in an incomplete market environment. However, in the context of an DD economy this information asymmetry argument is not convincing since the information constraints are not binding in the DD economy so that the first best (under publicly observable information) 
and the second best (under private information) solutions actually coincide. It is therefore far from obvious that asset markets shall not be able to generate the first best solution, i.e., the Pareto optimal allocation.

As this paper's main contribution, we prove that the optimal allocation of the original DD economy can be alternatively implemented through an intermediate asset market whenever the agents' ex ante investment decisions correctly anticipate the equilibrium on this market. That is, under the assumption that the agents fully understand how future equilibrium prices depend on today's investment decisions, even an idealized financial intermediary cannot outperform asset markets in terms of welfare generation.

\section{The optimal allocation}

This section derives the optimal allocation of the original DD economy. Suppose that all agents of the economy pool their wealth with a financial intermediary, i.e., an idealized bank, which maximizes each agent's ex ante expected utility subject to the bank's budget constraint. Formally, in period 0 every agent $i \in[0,1]$ deposits his initial wealth $W_{i}=1$ with the bank. The bank decides in period 0 which fraction of the accumulated wealth

$$
W=\int_{i \in[0,1]} W_{i} d i=1
$$

to hold as cash, $C$, and which fraction to hold as assets, $A$. The bank will earn in period 2 the certain return $R>1$ per unit of asset. In the intermediate period 1, every agent learns whether he has a low, $L$, or a high, $H$, patience for consumption. Denote by $c_{t}, t=1,2$, period $t$ consumption of an agent and consider the following type-dependent utility function over consumption streams

$$
U\left(c_{1}, c_{2}, \theta\right)= \begin{cases}u\left(c_{1}\right) & \text { if } \theta=L \\ u\left(c_{1}+c_{2}\right) & \text { if } \theta=H\end{cases}
$$


for some continuously differentiable, strictly increasing, and strictly concave function $u$ : $\mathbb{R} \rightarrow \mathbb{R}$.

Suppose that a low, resp. high, type agent receives in period 1 amount $C_{L}$, resp. $C_{H}$, of cash from the bank which he immediately consumes. Further suppose that the bank allocates to a low, resp. high, type agent the amount $A_{L}$, resp. $A_{H}$, of assets such that the agent consumes in period 2 the returns generated by these assets. Denote by $\pi(L) \in(0,1)$, resp. $\pi(H)=1-\pi(L)$, the probability that an agent has low, resp. high, patience for consumption. Then the agent's period 0 expected utility from the allocation $\left(C_{L}, A_{L}, C_{H}, A_{H}\right)$ is given as

$$
\begin{aligned}
& E U\left[C_{L}, A_{L}, C_{H}, A_{H}\right] \\
= & U\left(c_{1}, c_{2}, L\right) \cdot \pi(L)+U\left(c_{1}, c_{2}, H\right) \cdot \pi(H) \\
= & u\left(C_{L}\right) \cdot \pi(L)+u\left(C_{H}+R \cdot A_{H}\right) \cdot \pi(H) .
\end{aligned}
$$

Let us stipulate that the law of large numbers works to the effect that in the intermediate period 1 a mass $\tau=\pi(L)$ of agents will have low and a mass $1-\tau=\pi(H)$ of agents will have a high patience for consumption. ${ }^{1}$ Under the assumption that the agent's types are observable by the bank, the bank thus maximizes

$$
\begin{aligned}
& E U\left[C_{L}, A_{L}, C_{H}, A_{H}\right] \\
= & u\left(C_{L}\right) \cdot \tau+u\left(C_{H}+R \cdot A_{H}\right) \cdot(1-\tau) .
\end{aligned}
$$

subject to

$$
\tau \cdot\left(A_{L}+C_{L}\right)+(1-\tau) \cdot\left(A_{H}+C_{H}\right)=1 .
$$

For the optimal allocation $\left(C_{L}^{*}, A_{L}^{*}, C_{H}^{*}, A_{H}^{*}\right)$ it must obviously hold that $A_{L}^{*}=C_{H}^{*}=0$. By 
$(5)$,

$$
A_{H}^{*}=\frac{1-\tau \cdot C_{L}^{*}}{1-\tau}
$$

whereby $C_{L}^{*}$ is characterized by the following first order condition

$$
\begin{aligned}
\frac{d}{d C_{L}}(E U) & \equiv u^{\prime}\left(C_{L}^{*}\right) \cdot \tau-\tau \cdot R \cdot u^{\prime}\left(R \cdot \frac{1-\tau \cdot C_{L}^{*}}{1-\tau}\right)=0 \\
& \Leftrightarrow \\
u^{\prime}\left(C_{L}^{*}\right) & =R \cdot u^{\prime}\left(R \cdot \frac{1-\tau \cdot C_{L}^{*}}{1-\tau}\right)
\end{aligned}
$$

or, equivalently expressed (cf. Equation (1b) in DD) as

$$
u^{\prime}\left(c_{1}^{*}\right)=R \cdot u^{\prime}\left(c_{2}^{*}\right)
$$

where $c_{1}^{*}=C_{L}^{*}$ denotes the optimal period 1 consumption of the low patience and $c_{2}^{*}=$ $R \cdot \frac{1-\tau \cdot C_{L}^{*}}{1-\tau}$ denotes the optimal period 2 consumption of the high patience type. The following proposition collects the above results.

Proposition 1 (Diamond and Dybvig 1983): Suppose that the agents'types are publicly observable. Then the (first best) optimal allocation $\left(C_{L}^{*}, A_{L}^{*}, C_{H}^{*}, A_{H}^{*}\right)$ of the DD model is characterized by the following equations

$$
\begin{aligned}
A_{L}^{*} & =C_{H}^{*}=0, \\
A_{H}^{*} & =\frac{1-\tau \cdot C_{L}^{*}}{1-\tau}, \\
u^{\prime}\left(C_{L}^{*}\right) & =R \cdot u^{\prime}\left(R \cdot \frac{1-\tau \cdot C_{L}^{*}}{1-\tau}\right) .
\end{aligned}
$$


Now suppose that the agents' types are private knowledge and, therefore, not observable by the bank. In this situation of asymmetric information, the bank's optimization problem would have to take account of incentive compatibility constraints for each type. It is easy to see that the first best allocation of Proposition 1 satisfies the corresponding incentive compatibility conditions: First, a low patience type does not care about assets allocated to the high patience type. Second, the high patience type strictly prefers his allocated assets $A_{H}^{*}$ to $C_{L}^{*}$ because (12) implies $c_{2}^{*}>c_{1}^{*}$ since $R>1$ and $u^{\prime}$ is (by strict concavity of $u$ ) strictly decreasing. Consequently, the information constraints are not binding in this economy. ${ }^{2}$

Corollary: Suppose that the agents' types are not publicly observable. Then the (second best) optimal allocation of the original DD economy coincides with the (first best) optimal allocation $\left(C_{L}^{*}, A_{L}^{*}, C_{H}^{*}, A_{H}^{*}\right)$ of Proposition 1.

\section{Implementing the optimal allocation through an asset market}

This Section demonstrates that the optimal allocation of Proposition 1 can be implemented through an asset market if the agent's correctly anticipate the asset market's equilibrium price function. In addition to assets, which are claims to the returns of the long-term project, the agents now also hold some cash in period 0. This cash can be either used for consumption in periods 1 or 2 , or for purchasing further assets on the period 1 asset market. In period 0 the agent thus decides about how much of his initial wealth to hold as cash, $C$, versus to invest in the long-term project, $A=1-C$.

The following analysis proceeds backwards. At first, we describe the period 1 competitive asset market at which all agents can trade their assets after they have learnt their patience type. In a next step, we describe the period 0 investment situation of the representative agent who correctly anticipates how the period 1 equilibrium price is determined by his period 0 decision to hold cash versus assets. 
The period 1 asset market. Denote by $p$ the period 1 market price of a unit of asset. The supply-demand decisions of the agents at a given price $p$ depend on their type. For example, at a price $p$ such that $0<p<R$ a high patience type is interested in buying the asset whereas a low patience type is interested in selling the asset. More generally, we obtain the following aggregate supply, respectively demand, correspondences for assets in the period 1 asset market.

Aggregate supply of the asset at market price p:

$$
S(p)=\left\{\begin{array}{cc}
1-C & p>R \\
{[\tau \cdot(1-C), 1-C]} & p=R \\
\tau \cdot(1-C) & 0<p<R
\end{array}\right.
$$

Aggregate demand for the asset at market price p:

$$
D(p)=\left\{\begin{array}{cc}
0 & p>R \\
{\left[0,(1-\tau) \cdot \frac{C}{p}\right]} & p=R \\
(1-\tau) \cdot \frac{C}{p} & 0<p<R
\end{array}\right.
$$

Given the aggregate amount of money $C$, the period 1 asset market clears at equilibrium price $p^{*}$ if and only if

$$
\begin{aligned}
S\left(p^{*}\right) & =D\left(p^{*}\right) \Leftrightarrow \\
\tau \cdot(1-C) & =(1-\tau) \cdot \frac{C}{p^{*}} \Leftrightarrow \\
p^{*} & =\frac{(1-\tau)}{\tau} \cdot \frac{C}{(1-C)} .
\end{aligned}
$$


Note that in the market equilibrium all low patience types will only hold cash whereas all high patience types will only hold assets. More precisely, any low type will hold $C+(1-C) \cdot p^{*}$ units of cash and any high type will hold $1-C+\frac{C}{p^{*}}$ units of asset in the market equilibrium. The representative agent's expected utility in period 0 under the correct anticipation of this period 1 market equilibrium is therefore given as

$$
\begin{aligned}
E U\left(p^{*}\right) & =u\left(C+(1-C) \cdot p^{*}\right) \cdot \pi(L)+u\left(R \cdot\left(1-C+\frac{C}{p^{*}}\right)\right) \cdot \pi(H) \\
& =u\left(\frac{C}{\tau}\right) \cdot \pi(L)+u\left(R \cdot \frac{1-C}{1-\tau}\right) \cdot \pi(H)
\end{aligned}
$$

The period 0 investment situation. The period 1 equilibrium price for equity is, by (17), a function of the amount of cash, $C$, held in the aggregate, i.e., $p^{*} \equiv p^{*}(C)$. Suppose now that in period 0 the representative agent chooses $C$ in order to maximize the period 0 expected utility (18) whereby he correctly understands the equilibrium price function (17). The optimal period 0 amount of cash for every agent, denoted $C^{M}$, is then characterized as the solution to the following first order condition

$$
\frac{d}{d C}\left(E U\left[p^{*}(C)\right]\right) \equiv u^{\prime}\left(\frac{C^{M}}{\tau}\right)-R \cdot u^{\prime}\left(R \cdot \frac{1-C^{M}}{1-\tau}\right)=0
$$

Proposition 2: In the asset market equilibrium, every agent holds in period 0 the amount $C^{M}$ of cash and the amount $A^{M}=1-C^{M}$ of assets such that $C^{M}$ is characterized by the following equation

$$
u^{\prime}\left(\frac{C^{M}}{\tau}\right)=R \cdot u^{\prime}\left(R \cdot \frac{1-C^{M}}{1-\tau}\right)
$$


The period 1 equilibrium price is then given as

$$
p^{*} \equiv p^{*}\left(C^{M}\right)=\frac{(1-\tau)}{\tau} \cdot \frac{C^{M}}{\left(1-C^{M}\right)} .
$$

By (12) and (21), we obtain

$$
C_{L}^{*}=\frac{C^{M}}{\tau}
$$

for the relationship between the optimal amount of cash, $C_{L}^{*}$, allocated to every low patience type, on the one hand, and the optimal amount of cash, $C^{M}$, held by each agent in period 0 in the asset market situation, on the other hand. Because only low type agents hold in the asset market equilibrium cash in period 1 , every low type agent ends up with the same equilibrium amount of cash, i.e., $C_{L}^{*}$, as under the optimal allocation of Proposition 1. Similarly, after trading on the asset market every high type ends up with the same equilibrium amount of assets, i.e., $A_{H}^{*}$, as under the optimal allocation of Proposition 1.

We are now ready to state this paper's man result.

Theorem: The optimal allocation of Proposition 1 and the asset market equilibrium allocation of Proposition 2 are identical. In particular, we obtain for the agent's period 0 expected utility under both scenarios

$$
\begin{aligned}
E U\left[C_{L}^{*}, A_{L}^{*}, C_{H}^{*}, A_{H}^{*}\right] & =u\left(C_{L}^{*}\right) \cdot \pi(L)+u\left(R \cdot \frac{1-\tau \cdot C_{L}^{*}}{1-\tau}\right) \cdot \pi(H) \\
& =u\left(\frac{C^{M}}{\tau}\right) \cdot \pi(L)+u\left(R \cdot \frac{1-C^{M}}{1-\tau}\right) \cdot \pi(H) \\
& =E U\left[p^{*}\left(C^{M}\right)\right] .
\end{aligned}
$$




\section{Discussion}

Similar to our analysis, Hellwig (1994) describes a rather complex variant of an DD-type economy for which the optimal allocation could be implemented through an asset market. Hellwig (1994) proceeds to offer three possible reasons why financial intermediation may be nevertheless be superior to asset markets: Avoidance of market-transaction costs caused by spatial differentiation; a role as commitment device; and the monitoring-cost advantage argument by Diamond (1984) (see also Hellwig 1998).

The analysis of this paper points to a fourth reason that might make financial intermediation more attractive than participation in asset markets. Namely, the implementation of the optimal allocation through an asset market equilibrium is implicitly based on a strong common knowledge of rationality argument: Not only must every agent correctly anticipate the future market clearing price function, he must also rely on the other agents to correctly anticipate this correct market price function (and so forth...) so that all agents' decentralized period 0 investment decisions will aggregate up to the optimal amount of cash versus assets held in this economy. Although this coordination problem of decentralized market decisions has been simply assumed away by the construct of a representative agent with correct price anticipations, this does not mean that real-life agents do not feel uncomfortable

about relying on the common rationality of all agents. If, in contrast, only the financial intermediary has to make the aggregate investment decision, the complexity of this decentralized decision situation reduces to a simple centralized decision situation where only the financial intermediary has to be rational. 


\section{References}

Diamond, D.W. (1984) "Financial Intermediation and Delegated Monitoring," Review of Economic Studies 51, 393-414.

Diamond, D.W., and P.H. Dybvig (1983) "Bank Runs, Deposit Insurance, and Liquidity," Journal of Political Economy 91, 401-419.

Duffie, D., and Y. Sun (2007) "Existence of Independent Random Matching," The Annals of Applied Probability 17, 386-419.

Freixas, X., and J.C. Rochet (2008) Microeconomics of Banking, 2nd edn., The MIT Press, Cambridge, Massachusetts.

Hellwig, M. (1994) "Liquidity Provision, Banking, and the Allocation of Interest Rate Risk," European Economic Review 38, 1363-1389.

Hellwig, M. (1998) "Banks, Markets, and the Allocation of Risks in an Economy," Journal of Institutional and Theoretical Economics 154, 328-354.

Judd, K.L. (1985) "The Law of Large Numbers with a Continuum of iid Random Variables," Journal of Economic Theory 35, 19-25.

Postlewaite, A., and X. Vives (1987) "Bank Runs as an Equilibrium Phenomenon," Journal of Political Economy 95, 485-491.

Rochet, J.-C., and X. Vives (2004) "Coordination Failures and the Lender of Last Resort: Was Bagehot Right After All?," Journal of the European Economic Association 2, 1116-1147. 


\section{Notes}

*I would like to thank an anonymous referee for his helpful suggestions.

${ }^{\dagger}$ Department of Economics, University of Pretoria, Private Bag X20, Hatfield 0028, South Africa. E-mail: alexander.zimper@up.ac.za

${ }^{1}$ That the individual probability of an depositor to turn out as a high type coincides (almost surely) with the fraction of high types in the population, is for a countably infinite population justified by the law of large numbers together with the assumption that depositors' types are independently and identically distributed. While such justification is not at hand for the continuous population of our model (Judd 1982, Duffie and Sun 2007), we simply follow here the literature and misquote the law of large numbers in the 'usual way'.

${ }^{2}$ Diamond and Dybvig (1983) consider very concave $u$, i.e., $u$ has to satisfy

$$
\frac{-c u^{\prime \prime}(c)}{u^{\prime}(c)}>1 \text { for all } c \in \mathbb{R}_{+},
$$

which excludes, e.g., log-utility. The above analysis shows that strict concavity is already a sufficient condition for the results in Propositon 1 and the Corollary. 